\title{
Moderated Group Chat: An Empirical Assessment of a New E-Service Encounter
}

Citation for published version (APA):

van Dolen, W. M., \& de Ruyter, J. C. (2002). Moderated Group Chat: An Empirical Assessment of a New E-Service Encounter. International Journal of Service Industry Management, 13(5), 496-511.

https://doi.org/10.1108/09564230210447959

Document status and date:

Published: 01/01/2002

DOI:

10.1108/09564230210447959

Document Version:

Publisher's PDF, also known as Version of record

\section{Please check the document version of this publication:}

- A submitted manuscript is the version of the article upon submission and before peer-review. There can be important differences between the submitted version and the official published version of record.

People interested in the research are advised to contact the author for the final version of the publication, or visit the DOI to the publisher's website.

- The final author version and the galley proof are versions of the publication after peer review.

- The final published version features the final layout of the paper including the volume, issue and page numbers.

Link to publication

\footnotetext{
General rights rights.

- You may freely distribute the URL identifying the publication in the public portal. please follow below link for the End User Agreement:

www.umlib.nl/taverne-license

Take down policy

If you believe that this document breaches copyright please contact us at:

repository@maastrichtuniversity.nl

providing details and we will investigate your claim.
}

Copyright and moral rights for the publications made accessible in the public portal are retained by the authors and/or other copyright owners and it is a condition of accessing publications that users recognise and abide by the legal requirements associated with these

- Users may download and print one copy of any publication from the public portal for the purpose of private study or research.

- You may not further distribute the material or use it for any profit-making activity or commercial gain

If the publication is distributed under the terms of Article $25 \mathrm{fa}$ of the Dutch Copyright Act, indicated by the "Taverne" license above, 
IJSIM

13,5

496

\title{
Moderated group chat: an empirical assessment of a new e-service encounter
}

\author{
Willemijn M. van Dolen and Ko de Ruyter \\ Department of Marketing and Marketing Research, \\ Faculty of Economics and Business Administration, \\ Maastricht University, The Netherlands
}

Keywords Internet, Communication, Customer satisfaction, E-commerce, Service delivery system, Modelling

Abstract In this paper, the focus is on a new type of electronic service encounter called Moderated Group Chat (MGC). MGC is defined as on-line, real-time interactions between groups of customers with an active coordinating role for a company representative and a commercial objective. Based on the technology acceptance model, we develop a conceptual framework and examine empirically which factors drive customer satisfaction with MGC sessions. Particularly, we look at the impact of perceived usefulness, perceived ease of use and perceived enjoyment on customer satisfaction. As MGC involves multiple participants and interactions take place within an electronic group environment, predictor-criterion relationships may vary between individualand group-level or shared perceptions. Therefore, the relationships between aforementioned determinants and chat session satisfaction are tested using a multi-level model. In addition, group size was included as a control variable. Finally, since chat is an innovative service delivery channel, we also took a number of customer characteristics (i.e. innovativeness, experience with investing and experience with chat) into account. Whereas we find support for a positive impact of the majority of predictor variables on chat session satisfaction, the precise nature of the relationship varies across levels. Moreover, while group size is positively related to satisfaction, experience with investing exhibits a weakly negative relationship.

\section{Introduction}

The rapid diffusion of information and communication technology has had a pervasive impact on scale and scope of service delivery during the last past years (Prabhaker et al., 1997). Presented with the opportunities of intelligent interactivity, many service firms are experimenting with technology-mediated interactions for electronic (e-) service delivery (Bergeron, 2001). The interactive nature of e-services offers many opportunities to expand the efficiency of service delivery and many self-service business models have been implemented successfully in service industries, such as banking, brokerage and travel (de Ruyter et al., 2001). As a consequence, comparatively much attention has been directed at technology-based self-services, often through the lens of the Technology Acceptance Model (TAM) that has been developed in the area of information technology research (Davis, 1989). From this body of research, "usefulness", "ease of use" and "enjoyment" have emerged as drivers of customers' evaluative judgements of technology-mediated self-service modes (Dabholkar, 1994; Meuter et al., 2000; Szymanski and Hise, 2000). Additionally, consumer characteristics, such as experience and innovativeness, as well as

International Journal of Service Industry Management,

Vol. 13 No. 5, 2002, pp. 496-511. (C) MCB UP Limited, $0956-4233$ DOI 10.1108/09564230210447959 
situational differences, like the presence of other customers, have also been shown to have an impact on consumer evaluations of technology-based selfservices (Hui and Bateson, 1991; Fazio, 1995; Dabholkar, 1996).

However, following many negative accounts of e-service experiences by customers, service providers are increasingly aware that they need to complement the infusion of technology in virtual self-services with the social aspects and experiential value traditionally associated with (real-world) service delivery (Albrecht and Zemke, 2001). As a result, a number of companies have implemented Internet Relay Chat (IRC) in an attempt to make the e-service delivery more socially engaging and enhance its interactive richness and, thus, combine a focus on high-tech with high-touch. IRC does not only allow real-time human contact between customers and company, but also offers the possibility to interact with other customers. Part of the e-service offer by catalog retailer Land's End, for instance, includes the option for customers to chat with a service representative about products, shipping costs and delivery hours. Moreover, using IRC it is possible to shop or co-browse on-line with friends.

While it has been reported (e.g. O'Crockett, 2001) that IRC yields significantly higher visitor-buyer conversion rates, cross-selling opportunities and favorable e-loyalty scores, this e-service innovation has also been associated with the risk of uncontrollable behavior and trust and security issues. In order to realize the potential of IRC as an effective e-service delivery mode and stimulate widerscale acceptance, there is a need for an in-depth insight into the formation of customer satisfaction with IRC. Therefore, this research aims to extend the literature on technology acceptance to the new interpersonal e-service mode of IRC. In doing so, we take into account that the group communication involved in customer-to-customer interactions during IRC as an important social aspect of e-service delivery. As a result of group interaction, determinants of customer satisfaction may vary between individual- and group-level or shared perceptions. Therefore, the objective of this paper is to examine which factors drive customer satisfaction with IRC as an e-service delivery mode, focusing on both levels, the individual and the group.

The paper is structured as follows. First of all, we conceptualize IRC as an e-service delivery instrument. Second, we review the TAM-literature on customer evaluations of e-service delivery. After constructing a conceptual framework for explaining customer satisfaction with IRC, we report on the results of an experiment study aimed at empirically testing the framework within the context of financial services. We conclude the paper with a discussion of the theoretical and managerial implications and directions for future research.

\section{E-service delivery via IRC}

A chat session is a new and relatively unknown form of service encounter in which informational and social exchanges take place synchronously in an on-line environment. The prevalent modality of communication is written text, but audio-visual chat sessions have also been introduced recently. The combination 
IJSIM

13,5

498 of real-time interaction and real human contact make IRC particularly suitable for e-service delivery. Several applications of IRC as an e-service channel exist. In the first place, IRC has been used as a value-added service option to the buying or information-gathering process. The chat option can be used by customers to ask for information from a customer service representative on, for instance, the availability of products or warranties. Alternatively, service employees can track customers' information search behavior and open a dialog box to supply information. Second, IRC occurs in open chat rooms in virtual communities of interest and/or commerce. These chat sessions are primarily viewed as a service that facilitates the sharing of social exchanges. Service providers, such as Travelo-city and $\mathrm{E}^{*}$ trade provide these interactive spaces to their customers to build rapport and extract market information on issues that customers identify as relevant. A third service delivery application is to use IRC for the purpose of customer education within the context of new service development. Financial service providers like Merrill Lynch apply IRC within the context of on-line financial seminars in order to allow their customers to talk to financial experts regarding recently-launched investment services. Finally, a number of companies are organizing a moderated group chat (MGC). In this type of IRC, a company representative regulates and facilitates the electronic discussion among a group of customers. These sessions are pre-scheduled and offer customers to share their experience with a particular service. In contrast to the chat-based online seminar, the main emphasis is on interaction among customers. Pristine Real Time Trading, for instance, offers their customers the opportunity to subscribe to MGC aimed at sharing investment information and advice between financial advisors and fellow investors. In a similar fashion, American Express organizes chat sessions on financial issues for certain segments of customers. In this study, we focus on MGC.

After this brief overview of practical applications of IRC as an e-service delivery mode, we develop a conceptual framework that may be used for explaining customer evaluations of MGC as an e-service instrument in the next section of this article.

\section{Development of a conceptual framework}

In order to assess customers' evaluation of both off-line and on-line service encounters, satisfaction has been frequently identified as a critical effectiveness parameter (Bitner et al., 1990; Meuter et al., 2000; Szymanski and Hise, 2000). Therefore, the focus in this study is on customer satisfaction with the moderated chat session service encounter. In relation to chat session satisfaction, we take the view that a new service mode that is perceived to provide useful information in an easy-to-use, convenient and enjoyable manner will be considered to be satisfying. In this sense, satisfaction represents the sum of positive and negative evaluations to specific factors by individuals. As such, satisfaction is regarded as a domain-specific attitude. Although antecedents of satisfaction with off-line or face-to-face service encounters as well as customer evaluations of technology-based self-service encounters have 
been studied extensively (Oliver, 1997; Meuter et al., 2000), determinants of satisfaction with MGC have yet to be defined. Our point of departure for understanding customer evaluations of MGC is the TAM model that was originally developed for the study of information technology adoption (Davis, 1983, 1989). The TAM model, which has its roots in the theory of reasoned action (Fishbein and Ajzen, 1975), posits that a user's attitude towards a technology is dependent on two specific behavioral beliefs, perceived usefulness and perceived ease of use. In terms of the frequently made distinction between process and outcome in the services marketing literature, usefulness denotes the outcome of the e-service encounter, while ease of use refers to the process resulting in this outcome (Childers et al., 2001). In the case of a chat session, ease of use is related to the process of using this service for the benefit of its informational and/or social value. In addition, perceived enjoyment has often been added to point attention to more hedonic motivations of technology use or the gratification for its own sake, regardless of its performance or functional benefits (Davis et al., 1992). For the context of MGC, this leads to the following set of predictions:

H1. There will be a positive relationship between perceived usefulness and chat session satisfaction.

H2. There will be a positive relationship between perceived ease of use and chat session satisfaction.

H3. There will be a positive relationship between perceived enjoyment and chat session satisfaction.

As was mentioned above, both consumer and situational characteristics may also have an influence on customer evaluations with technology-mediated service delivery. One important motivating factor that may contribute to favorable evaluations of new technology is innovativeness. This construct reflects an important innate personality trait which has been studied widely in the consumer behavior field. Venkatraman and Price (1990), for instance, conceptualize innovativeness as a latent trait that predisposes consumers to try out new products or services and develop a favorable attitude towards these. It has its roots in diffusion of innovations theory and in this body of research it has been identified as an important determinant of acceptance and use of new technology (Rogers and Shoemaker, 1971). Innovativeness has been defined as "the degree to which an invidual is relatively earlier in adopting an innovation than other members of his or her social system" (Rogers and Shoemaker, 1971, p. 27). Consumers who display a relatively high level of innovativeness are inclined to evaluate technology and the use of technology-based services more positively, are more intrinsically motivated to use such services and appreciate new ways of doing things (Mehrabian and Russell, 1974; Midgley and Dowling, 1978). Therefore, we hypothesize that:

H4. There will be a positive relationship between innovativeness and chat session satisfaction. 
IJSIM

13,5

500
It has been argued that the acceptance of new technology is largely a function of the level of prior experience (Fazio, 1995). It is contended that evaluations are frequently activated automatically when a subject is confronted with an object that is related to prior experience. Subsequently, through a process of selective perception, former experience guides the evaluation of an attitude object. Fazio and Zanna (1978) demonstrate that evaluations from people who have had prior experience with an attitude object were stronger related to consequent attitude-related behavior than people without direct experience. In the case of chat as a service channel it seems relevant to make a distinction between the medium and the message. On the one hand, prior experience with chat as a new service mode and, on the other hand, experience with the specific service domain will have an impact on customer evaluations. Therefore, based on the prior experience research in relation to new technology we contend that:

H5. There will be a positive relationship between experience with investing and chat session satisfaction.

H6. There will be a positive relationship between experience with chat and chat session satisfaction.

Finally, as MGC involves consumers sharing information and experience within the context of a group, it seems relevant to take group size into account as a situational variable. From the organizational literature on teams (Campion et al., 1993), it has become clear that group size is related to (job) satisfaction. As can be expected, this relationship is frequently non-linear. On the one hand, there has to be a minimum number of participants present in the chat sessions to generate the informational and social benefits associated with group communication. On the other hand, if the group is too large, this will hinder efficient communication and information processing, resulting in lower levels of satisfaction. Therefore, we decided to include group size in our conceptual framework as a control variable in order to determine its effect on chat session satisfaction within the given range of group sizes with our study.

\section{Refinement of the conceptual framework}

As was stated above, one of the unique properties of MGC is that it involves multiple persons and is therefore by definition a social experience. As a result, the formation of satisfaction may not uniquely depend on the perceptions of individual participants, but also on the shared perceptions of the collective group members. In a chat session, participants do not only process information at the individual level, but also at the level of the group. Due to the hierarchical structure of group data (i.e. participants nested within chat groups) the variance of the predictors (i.e. perceived usefulness) can be distinguished into two sources: group factors and individual's subjective assessment (Van Yperen and Snijders, 2000). Decomposing the variance into the distinct components enables us to disentangle the subjective interpretation from the group factor. As different levels signify different meanings, it makes sense to consider both 
levels simultaneously. More specifically, aggregated data correspond to the inter-subjective perceptions of participants' satisfaction. If consumers within the chat group respond to some extent in a similar way (e.g. James, 1982), group averages are suggested to be more reliable and better indicators of the actual (i.e. true) group situation than any single individual's score (e.g. Campion et al., 1993). Conversely, the individual data refer to subjective appraisals of the chat session. Recent empirical studies have demonstrated that within-group deviation of variables not only concerns random error, but also reflects systematic variance, i.e. actual individual differences (Ostroff 1993, Van Yperen and Snijders, 2000), which may be caused by the diversity in participant characteristics (Klein et al., 2001, Ostroff, 1993, Van Yperen and Snijders, 2000) or the idiosyncratic way in which perceptions of the chat session are formed. Perceptions change through valuation into personal opinions, in which a cognitive representation of environmental aspects is interpreted by means of individual's values. Obviously, group level effects may be expected only for those variables pertaining to the chat session process, in contrast to the individual, participant characteristics. Therefore, our research aims to answer the following research question in relation to chat session satisfaction:

$R Q 1$. To what extent do the effects of the predictor variables related to the properties of the chat session (usefulness, ease of use, and perceived enjoyment) on chat session satisfaction operate at the group-level or the individual level or both?

In the next section we report on a study designed to empirically test our hypotheses and answer this research question.

\section{Methodology}

Research design

To test our hypotheses we organized chat sessions in an experimental research laboratory. During these sessions, respondents chatted with an advisor and other customers about two financial investment funds. The context of financial advice was selected since we felt that investing is a topic that would interest most respondents and many chat sessions on this topic actually take place on the Internet.

Groups of three to seven persons were invited for each chat session. The session started with an introduction in which it was explained that the respondents were going to chat about investment funds together with other customers and an advisor of a bank. Next it was explained that she/he planned to invest $€ 1,500$ and a short description of the funds was given. Subsequently, the chat session began.

In total, 38 groups were formed. Participants in this research were 198 business students from a large Dutch university. They received course credits for their participation. Half of the sample were men and half were women, with an average age of 21 years. 
IJSIM

13,5

502

\section{Measures}

Satisfaction with the chat session was measured on a nine-item, equally weighted scale. We used all items as suggested by Evans et al. (2000). We complemented this scale with two items: "Based on my experience, I am satisfied with this advisory service; In general, I am satisfied with this service provider". The constructs usefulness, ease of use, and enjoyment were measured by four items for each construct, using seven-point Likert-scales ranging from "totally disagree" to "totally agree". The scale of usefulness included items: This chat session was useful". An example-item for ease of use is: "This investment advisory service was complicated" (reverse coded) and for enjoyment: "This investment advisory service was enjoyable". Innovativeness was measured by three items: "In general, I am the first in my circle of friends to try new interactive services". Experience with investing and experience with chat were both measured by one item using a seven-point Likert-scale ranging from "not at all" to "very much". The items were respectively: "How experienced are you regarding investing?" and "How experienced are you regarding chat?".

Construct reliabilities of all scales (except experience with investing and experience with chat) were tested by means of Cronbach's alpha. Coefficients of all measures were higher than 0.86 , which implies that reliability is deemed acceptable. Correlations between the variables at both levels are presented in Table I.

\section{Multi-level analysis}

A multi-level model is a statistical model that takes into consideration withingroup variability as well as between-group variability. To compare withingroups and between-group coefficients of variables, variables are split into the group mean and the within-group deviation variable (individual score minus the group mean). The coefficient of the group-mean measures the betweengroups effect, whereas the coefficient of the within-group deviation scores

\begin{tabular}{lcrrrrrrrr}
\hline Variables & Mean (sd) & 1 & 2 & 3 & 4 & 5 & $6^{\mathrm{a}}$ & $7^{\mathrm{a}}$ & $8^{\mathrm{a}}$ \\
\hline 1. Satisfaction & $4.08(1.58)$ & & 0.14 & 0.35 & 0.38 & 0.10 & & & \\
2. Usefulness & $5.07(1.04)$ & 0.25 & & 0.20 & 0.12 & -0.42 & & & \\
3. Ease of use & $4.83(1.42)$ & 0.45 & 0.08 & & & -0.20 & & & \\
4. Enjoyment & $4.95(1.31)$ & 0.61 & 0.29 & 0.38 & & 0.13 & & & \\
5. Group size & $6.03(1.18)$ & - & -0.17 & -0.11 & 0.07 & & & & \\
6. Innovativeness & $3.55(1.52)$ & 0.23 & 0.17 & 0.19 & 0.22 & -0.06 & & & \\
7. Experience in investing & $3.00(1.79)$ & -0.10 & -0.07 & 0.10 & -0.08 & 0.02 & 0.20 & & \\
8. Experience in chat & $4.26(1.80)$ & 0.08 & 0.15 & 0.05 & 0.10 & -0.10 & 0.51 & 0.10 &
\end{tabular}

\section{Notes:}

Table I.

Means, standard deviations, and correlations
Individual-level correlations are in the lower triangle and group-level correlations are in the upper triangle.

a These variables are conceptualized as general constructs and are not included in our research as group-level variables. All correlations $>0.10$ are significant at $p<0.05$ (one-tailed) 
measures the within-group effect (Snijders and Bosker, 1999). To interpret both coefficients it is of interest to investigate whether the within-group deviation coefficient and the between-groups coefficient are equal. First, if these two coefficients are significant and equal, the variable functions at the individual-level, while there is no separate main effect at the group-level. Second, if the coefficient is significant for the group mean, but not significant for the within-group deviation, the effect emerges only at the group-level. Third, if the coefficient is significant at the individual level and not significant for the group mean, the effect is solely based on the subjective experience of the customer. Fourth, if both group mean and the within-group coefficient are significant, but different from each other, there exist both an individual effect and an independent group-level effect.

In our study, a two-level model was specified for the dependent variable "chat" session satisfaction to test its relationships with its antecedents empirically. Level one of the model concerns the within-group deviation scores of the variables and level two reflects the group means of the variables. To examine within-group agreement and therefore justification for aggregation of the group variables to the group mean, the variance of all study variables was decomposed into variance at the group-level and at the individual-level (Van Yperen and Snijders, 2000). The ratio of group-level variance to group-level plus individual-level variance is the intra-class correlation coefficient. This expresses the degree of resemblance between individual-level units belonging to the same group-level unit. If there is considerable resemblance, aggregation to the group mean is allowed. Also for the dependent variable, variance is decomposed in group-level and individual-level variance. If there is considerable variation at the group-level, multi-level analysis is appropriate.

The fixed effects of single predictor variables are comparable with regression coefficients in ordinary regression analysis. These were tested by means of onetailed $t$-tests, the test statistic being the coefficient divided by its standard error (Snijders and Bosker, 1999). The predictive power of the models can be compared by a likelihood ratio test. We tested for multivariate significance of effects by computing the increase in model fit compared to the previous step. The increase in model fit is represented by a decrease in deviance, where deviance is defined as $-2 \ln$ (likelihood). The difference between the deviance statistics ( $\Delta$ Deviance) has a $\chi^{2}$-distribution (with the number of added predictors as degrees of freedom) under $H O$ that the model does not predict significantly better than the previous model. The multi-level models were analyzed through the computer program MLwiN (Rasbash et al., 2000).

\section{Results}

Group-level variance and individual-level variance of usefulness, ease of use, enjoyment and satisfaction were decomposed to examine within-group agreement and between group differences. The results indicate that intra-class correlations were at least 0.10 . This suggests that perceptions of these variables were partly shared by the other customers in the chat group. Thus, for the 
IJSIM

13,5

504 predictor variables, it was appropriate to add them to the model as group-level variables. The intra-class correlation of chat session satisfaction indicates that a multi-level approach is appropriate. Regarding innovativeness, experience with investing, and experience with chat we did not expect any between-group variance. We conceptualized these variables as general constructs which are related to the individual consumer. Therefore, they were measured before the chat session took place and they are introduced in the model as individual-level variables.

Table II presents the results of our multi-level analyses regarding chat session satisfaction. The results indicate that, at the individual-level, usefulness is not significant. Therefore, $H 1$ has to be rejected. Ease of use and enjoyment at the individual-level are significant. Therefore, $H 2$ and $H 3$ are accepted.

At the group-level, usefulness, ease of use and enjoyment are significant. The coefficients of usefulness and ease of use are significantly higher compared to the within-group deviation coefficient of these variables[1]. Therefore, we may conclude that these effects operate at both levels and $H 1$ and $H 2$ are accepted at the group-level. Enjoyment is significant at both levels, but the difference between the coefficients is not significant, so the effect only operates at the individual-level.

The results show that innovativeness is significant, and therefore $\mathrm{H} 4$ is accepted. Experience with investing is also significant; however, this effect

\begin{tabular}{lc}
\hline Dependent variable: chat session satisfaction & ${\text { Coefficients }(\mathrm{SE})^{\mathrm{a}}}^{\mathrm{a}}$ \\
Control variable & $0.19(0.10)^{\mathrm{c}}$ \\
Group size (Level 2) & \\
Level $1^{\mathrm{b}}$ & $0.06(0.08)$ \\
Usefulness & $0.24(0.07)^{\mathrm{d}}$ \\
Ease of use & $0.57(0.08)^{\mathrm{d}}$ \\
Enjoyment & \\
Level 2 & $0.54(0.28)^{\mathrm{c}}$ \\
Usefulness & $0.43(0.15)^{\mathrm{d}}$ \\
Ease of Use & $0.47(0.17)^{\mathrm{d}}$ \\
Enjoyment & \\
Level $1^{\mathrm{b}}$ & $0.11(0.06)^{\mathrm{c}}$ \\
Innovativeness & $-0.07(0.04)^{\mathrm{c}}$ \\
Experience with investing & $-0.01(0.05)$ \\
Experience with chat & $\chi^{2}(10)=134.3^{\mathrm{e}}$ \\
Total increase in model fit & \\
Notes: & \\
${ }^{\mathrm{a}}$ Unstandardized coefficients with their standard errors & \\
${ }^{\mathrm{b}}$ Within-group deviation score $X_{i j}-X_{j}$ & \\
${ }^{\mathrm{c}} p<0.05$ (one-tailed) & \\
${ }^{\mathrm{d}} p<0.01$ (one-tailed) & \\
${ }^{\mathrm{e}} p<0.05$ &
\end{tabular}

\section{Table II.}

Results of the multilevel analyses 
is negative which is contrary to our expectations. Finally, experience with chat is not significant. Therefore, $H 5$ and $H 6$ have to be rejected.

From the results as discussed in relation to the hypotheses, we conclude that chat session satisfaction is influenced by both the individual's subjective and shared perceptions of the variables $(R Q 1)$. Finally, the results show that the control variable group size is significant. This control variable could only be introduced at the group-level; the group defines the group-level and consequently group size is a group-level variable by definition in our model.

\section{Discussion and implications}

The objective of this paper was to examine which factors drive customer satisfaction with IRC as an e-service delivery mode, while taking into account individual- and group-level processes. Our findings indicate that chat session satisfaction is influenced by both the individual's subjective experience, as well as by the shared perceptions of customers.

The effects of usefulness, ease of use, and enjoyment

It has been argued that e-service in its present stage may still be more likely to be goal-focused and driven by utilitarian motives rather than by experiential and hedonic ones. Goal-focused customers are transaction-oriented; they surf only when they have a specific purpose in mind and desire to purchase what they want quickly (Wolfinbarger and Gilly, 2001). Our findings on MGC create a more nuanced picture of e-service experiences. Our study found that at the individual level, customer perceptions of ease of use and enjoyment were important determinants of satisfaction. This suggests that satisfaction with MGC stems from the fact whether customers perceived the service delivery as easy to use and enjoyable. Perceptions of ease of use refer to the process of using chat while engaging in e-service encounters and may be created by the fact that MGC enables customers to obtain advice from several sources (e.g. the advisor and other customers) from the comfort of their homes. This may be perceived as an easy way of gathering information. It also might refer to the design of the software and Web page that customers used to chat. The importance of enjoyment indicates that the chat session itself is perceived to provide reinforcement in its own right. This might be created by the real-life interaction with other human beings on-line (e.g. Hoffman and Novak, 1996). Research demonstrates that other customers may have the ability to create an enjoyable experience and have a positive influence on the climate during the interaction (e.g. Deighton et al., 1989; Grönroos, 1990; Grove and Fisk, 1997).

The results with respect to the influence of shared experiences on satisfaction shows that usefulness and ease of use have significant group-level effects which are independent of their individual-level effects. Especially, the effect of usefulness is notable since this construct was not significant at the individual-level. This implies that only the shared experiences of customers regarding the outcome of the shopping experience is of influence. Seemingly, they process information about the usefulness through group discussion. 
IJSIM

13,5

506
Regarding ease of use, we may conclude that not the individual perceptions of the customers are of influence but also the shared experience of ease of use within the group results in satisfaction. Furthermore, it appears that the influence of enjoyment is an individual-level effect, implying that enjoyment while chatting is solely a subjective and individual experience.

The influence of shared experiences implies that firms would need a focus on the management of group processes during the chat session. Group processes may be stimulated by the advisor who moderates the chat session. Also, tools might be installed within the chat mode. For instance, by highlighting important episodes and questions which still have to be answered, the usefulness of the chat session might be enhanced.

Overall, our results suggest that customers experience MGC as useful, easy to use, and enjoyable. This indicates that customers associate utilitarian as well as hedonic aspects with on-line interactive services. Customers feel that MGC is useful and additionally enjoy the social aspects. The activity of MGC seems to be perceived as enjoying it in its own right. Consequently, we argue that the notion that on-line buyers do not desire "high-touch" services, as stated by Wolfinbarger and Gilly (2001), should be nuanced. It might be that this belief stems from the fact that many commercial Web sites just do not fully explore the interactive capabilities of the Internet. The Internet is the most conversational mass medium ever developed, yet most sites are not offering the possibilities of extended dialogue (Kirsner 1997). New technologies may change this if we use them well. Until recently, the experiential qualities of off-line shopping met needs that could not be met on Web sites. However, we argue that with the inventory of new interactive services that include human elements experiential needs can be met.

In line with the findings of Childers et al. (2001), our findings emphasize that a technology-oriented perspective that attempts to treat on-line shopping delivery modes as goal-oriented information systems, rather than hedonic and social environments, is likely to be fundamentally misguided. In general, our paper challenges research that suggests that an enjoyable and hedonic experience is hardly possible in CMC and that on-line shoppers largely like the lack of social interaction while shopping on-line. However, it is important to note that the findings suggest that customers do not only appreciate the fun aspects but they appreciate the usefulness as well. Rather, while designing encounters, instrumental characteristics must be considered in conjunction with the social criterion. Firms should use a technology that is fun and easy to use. Favorable perceptions of ease of use may be created by the design, but also by the advisor or other customers who explain and help during the chat session. Also, the fun element might be created by the other customers, as well as by colorful and humorous aspects in the design.

The effects of innovativeness, experience with investing and chat, and group-size Our results show that customers who are more innovative and who are the first in their circle of friends to try new interactive services, are more satisfied with 
MGC. This is understandable given the fact that chat in a commercial context is fairly new and the frame of reference to guide their behavior in this context is unknown yet. It is well known that in these circumstances more innovative people are more satisfied.

Interestingly, experience with chat is not significant and experience with investing is negatively related to satisfaction. We did not expect these results based on the literature that shows that in the case of new products and services prior experience will be the primary determinant of influence (Johnson and Fornell, 1991). However, our results are in line with results from the information systems literature that reveal that prior experience with information technology is negatively related to user satisfaction (Nash and Wilson, 1991; DiMartino and Zoe, 1996). It is argued that prior experience is not easily transferable from technology to technology and that relatively sophisticated users may develop unrealistic levels of confidence regarding their ability to successfully use new technology. Also, prior experience frequently involves having encountered negative aspects usually denoted as early adopter risks. Alternatively, it is argued that inexperienced users stand a greater chance of having their expectations surpassed by the new technology.

The findings of innovativeness and the experience of the customer imply that attention should be paid to the composition of chat groups. It seems valuable to focus on customers who are innovative, but not specifically on customers with experience with regard to the medium, e.g. chat, or the message.

Finally, we find that group size is positively related to satisfaction. This implies that groups with more respondents are more satisfied. This might be caused by the fact that with more customers there are more stories and experiences of other customers to share. Since "sharing with other customers" is one of the unique aspects of MGC, compared to dyadic chat or self-service Web sites, it is understandable that customers appreciate larger groups. Although groups of seven people (the maximum in our study) seem to have a positive effect on satisfaction, the relative increase in group size is certainly not unlimited. When groups become too large the chat session might become chaotic and difficult to follow. In sum, it seems that the very nature of MGC has several features that influence people's evaluation of this service delivery mode. It has aspects that are associated with goal-oriented shopping behavior, it includes human elements which respond to the call of customers for the integration of technology with human touch, and it seems to create unique elements related to the group aspects that are hardly found in off-line settings.

\section{Theoretical implications and future research}

Part of the strength of a research project lies in the acknowledgement of its limitations. These limitations may serve as points for a future research agenda. To begin with, our results are based on an experimental study. Therefore, the generalizability is limited with regards to real-life settings. Our findings should be examined in real-life settings as well as in other types of service settings. 
IJSIM

13,5

508
In testing the link between the predictors and chat session satisfaction, different levels of analysis were considered. Respondents' scores were aggregated at the group-level to compare consistency of relationships across levels. An important drawback, however, remains common method variance, which may have inflated the relationships estimated between the constructs and chat session satisfaction. For future research, we recommend the use of multiple independent data sources.

Furthermore, our study focused only on a subset of possible antecedents of MGC. For example, group characteristics like group cohesion and groupefficacy might be of influence, too. Additionally, the style of the advisor is a potential important predictor of the shopping experience. It is well known that, in off-line contexts, the behavior service employee influences the customer's satisfaction with the interaction (Price $e$ t al., 1995). Other characteristics like the shopping environment, e.g. hedonic vs. utilitarian (Childers et al., 2001) may also contribute to the shopping experience. Finally, factors like the physical environment in which customers experience electronic encounters, the design characteristics of interactive shopping sites, role clarity within the group, motivation, and customer ability affect on-line shopping behavior. Thus, increasing the range of antecedents is a clear next step in the research of MGC.

Furthermore, given the proliferation of electronic encounters, it is important to understand the factors that influence adoption of this new generation of customer touch points and to investigate the role of electronic encounters within a multi-channel strategy of a firm. In this paper, we do not make comparisons in that respect between face-to-face encounters, service provision via Web site without any human contact (e.g. self-service), and moderated electronic encounters. Further research could be designed specifically to allow comparisons between these type of service provisions. For instance, research could examine what motivates people to use electronic self-service encounters instead of face-to-face and/or moderated electronic encounters. Research on new media also shows that the use of new media creates a greater use of all existing communication channels (Lind and Zmud, 1995). Understanding the choices of customers to participate in face-to-face encounters as well as to use (self-service) electronic encounters may help managers to develop an integrated strategy. Effective management of all customer-firm service delivery and product selling options can be an excellent means of creating competitive advantage. When the appropriate mix of these customer-firm options is better understood, effective management of these channels may increase profitability and success in the increasingly competitive marketplace.

Further, future research needs to take into account the various levels of analysis. The paper emphasizes the value of a multi-level approach, since both individual-level and group-level variables were crucial in explaining variance in chat session satisfaction. The different levels of analysis reflect qualitatively different perspectives; individual data correspond to subjective appraisal processes, while aggregated data correspond to the inter-subjective perceptions. The question whether individual reports of satisfaction are a 
function of group factors rather than a result of an individual's subjective perceptions merits research attention (van Yperen and Snijders, 2000). Work in interpersonal influence as demonstrated by the group-level effects is needed since these effects are perhaps the quintessential indicators of interpersonal processes. Little research has been done with respect to these effects in the marketing context and the surface has been barely scratched. All too often, group researchers estimate individual-level effects or group-level effects, but fail to study both at the same time. Future research may also wish to consider which processes are operating behind the group-level effects.

In addition, from our study it has become clear that predictor-performance relationships appear to be consistent across levels for some variables, while subtly, but relevant, variations are found for other variables. Future research may extend the present study and investigate other types of variables as well as other types of service settings to determine whether these contingencies are based on underlying structural patterns.

Note

1. To test whether within- and between-group regressions are different, the significance of the group mean $X_{j}$ is tested, while controlling for the effect of the original variable, $X_{i j}$. If this coefficient is significant, then it is convenient to replace $X_{i j}$ by the within-group deviation score, defined as $X_{i j}-X_{j}$. This deviation score, together with the group mean, can be used to test if the within-group or between-group regressions are $O$ (Snijders and Bosker, 1999).

\section{References}

Albrecht, K. and Zemke R. (2001), Service America in the New Economy, McGraw-Hill, New York, NY.

Bergeron, B. (2001), The Eternal E-Customer, McGraw-Hill, New York, NY.

Bitner, M.J., Booms, B.H. and Tetreault, M.S. (1990), "The service encounter: diagnosing favorable and unfavorable incidents", Journal of Marketing, Vol. 54 No. 1, pp. 71-84.

Childers, T.L., Christopher, C.L., Peck, J. and Carson, S. (2001), "Hedonic and utilitarian motivations for online retail shopping behavior", Journal of Retailing, Vol. 77, pp. 511-35.

Campion, M.A., Medsker, G.J. and Higgs, C.A. (1993), "Relations between work group characteristics and effectiveness: implications for designing effective work teams", Personnel Psychology, Vol. 46, pp. 823-50.

Dabholkar, P.A. (1994), "Incorporating choice into an attitudinal framework: analyzing models of mental comparison processes”, Journal of Consumer Research, Vol. 21 No. 1, pp. 110-18.

Dabholkar, P.A. (1996), "Consumer evaluations of new technology-based self-service options: an investigation of alternative models of service quality", International Journal of Research in Marketing, Vol. 13, pp. 29-51.

Davis, F.D. (1989), "Perceived usefulness, perceived ease of use, and user acceptance of information technology”, MIS Quarterly, Vol. 13 No. 3, pp. 319-40.

Davis, F.D., Bagozzi, R.P. and Warshaw, P.R. (1992), "Extrinsic and intrinsic motivation to use computers in the workplace", Journal of Applied Social Psychology, Vol. 22 No. 14, pp. 1109-30.

Deighton, J., Romer, D. and McQueen, J. (1989), “Using drama to persuade”, Journal of Consumer Research, Vol. 16, December, pp. 335-43. 
IJSIM 13,5

510
DiMartino, D. and Zoe, L.R. (1996), "End-user full-text searching: access or excess?", Library \& Information Science Research, Vol. 18, Spring, pp. 133-49.

Evans, K.R., Kleine, R.E., Landry, T.D. and Crosby, L.A. (2000), "How first impressions of a customer impact effectiveness in an initial sales encounter", Journal of the Academy of Marketing Science, Vol. 28 No. 4, pp. 512-26.

Fazio, R.H. (1995), "Attitude accessibility and motivation as determinants of biased processing: a test of the MODE model”, Personality and Social Psycholgy, Vol. 21 No. 7, pp. 704-10.

Fazio, R.H. and Zanna, M.P. (1978), "Attitudinal qualities relating to the strength of the attitudebehavior relationship”, Journal of Experimental Social Psychology Bulletin, Vol. 21 No. 7, pp. 704-10.

Fishbein, M. and Ajzen, I. (1975), Belief, Attitude, Intention, and Behavior, Addison-Wesley, Reading, MA.

Grönroos, C. (1990), "Relationship approach to marketing in services contexts: the marketing and organizational behavior interface”, Journal of Business Research, Vol. 20, January, pp. 3-11.

Grove, S.J. and Fisk, R.P. (1997), "The impact of other customers on service experiences: a critical incident examination of 'getting along”, Journal of Retailing, Vol. 73 No. 1, pp. 63-85.

Hoffman, D.L. and Novak, T.P. (1996), "Marketing in hypermedia computer-mediated environments: conceptual foundations", Journal of Marketing, Vol. 60, Winter, pp. 50-68.

Hui, M. and Bateson, J.E.G. (1991), "Perceived control and the effects of crowding and consumer choice on the service experience", Journal of Consumer Research, Vol. 18, pp. 174-84

James, L.R. (1982), “Aggregation bias in estimates of perceptual agreement”, Journal of Applied Psychology, Vol. 67, pp. 219-29.

Johnson, M.D. and Fornell, C. (1991), "A framework for comparing customer satisfaction across individuals and product categories”, Journal of Economic Psychology, Vol. 12 No.2, pp. 267-86.

Kirsner, S. (1997), "Close encounters: the most effective Web sites offer users a conversation, not a monologue”, CIO Web Business Magazine, available at: www.cio.com/archive/ webbusiness

Klein K.J., Conn, A.B., Smith, D.B. and Sorra, J.S. (2001), "Is everyone in agreement? An exploration of within-group agreement in employee perceptions of the work environment", Journal of Applied Psychology, Vol. 86 No. 1, pp. 3-16.

Lind, M. and Zmud, R. (1995), "Improving interorganizational effectiveness through voice mail facilitation of peer-to-peer relationships", Organization Science, Vol. 6 No. 4, pp. 445-62.

Mehrabian, A. and Russell, J.A. (1974), "A verbal measure of information rate for studies in environmental psychology”, Environment and Behavior, Vol. 6, pp. 233-52.

Meuter, M., Ostrom, L., Roundtree, A.L., Robert, I. and Bintner, M. (2000), "Self-service technologies: understanding customer satisfaction with technology-based service encounters", Journal of Marketing, Vol. 64 No. 3, pp. 50-64.

Midgely, D.F. and Dowling, G.R. (1978), "Innovativeness: the concept and its measurement", Journal of Consumer Research, Vol. 4, pp. 227-42.

Nash, S. and Wilson, M. (1991), "Value-added bibliographic instruction: teaching students to find the right citations", References Services Review, Vol. 19, pp. 87-92.

O' Crockett, R. (2001), “Chat me up ... please”, Business Week Ebiz, 19 March.

Oliver, R.L. (1997), Satisfaction: A Behavioral Perspective on the Consumer, McGraw-Hill, New York, NY.

Ostroff, C. (1993), "Comparing correlations based on individual-level and aggregated data", Journal of Applied Psychology, Vol. 78 No. 4, pp. 569-82. 
Prabhaker, P., Sheehan, M. and Coppett, J.I. (1997), “The power of technology in business selling: call centers", The Journal of Business and Industrial Marketing, Fall.

Price, L., Arnould, E. and Deibler, S. (1995), "Consumer's emotional responses to service encounters. The influence of the services provider", International Journal of Service Industry Management, Vol. 6 No. 3, pp. 34-63.

Rogers, E.M. and Shoemaker, F.F. (1971), Communication of Innovation, The Free Press, New York, NY.

Rasbash, J., Browne, W., Goldstein., H., Yang, M. et al. (2000), A user's guide to MLwiN, 2nd ed., Institute of Education, London.

de Ruyter, J.C., Wetzels, M.G.M. and Kleijnen, M. (2001), "Customer adoption of e-service: an experimental study”, International Journal of Service Industry Management, Vol. 12 No. 2, pp. 184-206.

Snijders, T. and Bosker, R. (1999), Multilevel Analysis: an Introduction to Basic and Advanced Multilevel Modeling, Sage Publications, London.

Szymanski, D.M. and Hise, R.T. (2000), "E-satisfaction: an initial examination", Journal of Retailing, Vol. 76 No. 3, pp. 309-22.

van Yperen, N. and Snijders, T. (2000), "A multilevel analysis of the demands-control model: is stress at work determined by factors at the group level or the individual level?", Journal of Occupational Health Psychology, Vol. 5, pp. 182-90.

Venkatraman, M.P. and Price, L.L. (1990), "Differentiating between cognitive and sensory innovativeness: concepts, measurement and implications", Journal of Business Research, Vol. 20, pp. 293-315.

Wolfinbarger, M. and Gilly, M. (2001), "Shopping online for freedom, control, and fun”, California Management Review, Vol. 43 No. 2, pp. 34-56. 